\title{
LA SUSPENSION DEL OTORGAMIENTO DE LICENCIAS EN LA LEY DE MEDIDAS DE ADECUACION DEL ORDENAMIENTO URBANISTICO DE CATALUÑA (*)
}

\author{
352.778.511.711 (46. Cataluña)
}

por

\section{Antonio Carceller Fernández}

Profesor Titular de Derecho Administrativo

SUMARIO: I. INTRODUCCION.-II. SUSPENSION DEL OTORGAMIENTO DE LICENCIAS EN GENERAL: 1. CONCEPTO Y NAturaleza. 2. Distinción de otras figuras afines. 3. DEREC HO COMPARADO. 4. ANTECEDENTES Y EVOLUCION DE SU RÉGIMEN EN EL DERECHO ESPAÑOL.-III. ORDENAMIENTO URBANISTICO DE CATAluña: 1. Proyecto de Ley autonómica. 2. Ley de Medidas DE ADECUACIÓN: A) Tratamiento de la suspensión del otorgamiento de licencias. B) Suspensión potestativa. C) Suspensión automática. D) Otras disposiciones.-IV. CONCLUSIONES.

\section{INTRODUCCION}

La Ley 3/1984, de 9 de enero, de Medidas de Adecuación del Ordenamiento Urbanístico de Cataluña aparece, junto con la de Protección de la Legalidad Urbanística y con otra programada de Re-

(*) Texto de la Ponencia desarrollada sobre el mismo tema en el Seminario sobre la Ley de Medidas de Adecuación del Ordenamiento Urbanístico de Cataluña, organizado conjuntamente por el Departamento de Derecho Administrativo de la Facultad de Derecho de Barcelona y el Ayuntamiento de la Ciudad Condal. 
novación y Rehabilitación de Núcleos Urbanos, como un primer conjunto de medidas que van a establecer, en el marco general urbanístico vigente en el Estado, las bases jurídicas que van a permitir afrontar la recuperación urbana de Cataluña a lo largo de estos años ochenta (1).

Antes de entrar en el análisis del texto legislativo autonómico -objeto principal de este trabajo- vamos a hacer una referencia general a la suspensión del otorgamiento de licencias estudiando, aunque sea sumariamente, su concepto y naturaleza, su distinción de otras situaciones afines y los antecedentes que encontramos tanto en nuestro ordenamiento jurídico como en el Derecho comparado.

\section{SUSPENSION DEL OTORGAMIENTO DE LICENCIAS EN GENERAL}

\section{ConCEPTO Y NATURALEZA}

La suspensión del otorgamiento de licencias es una medida cautelar establecida con la finalidad de salvaguardar la eficacia de las previsiones sobre reforma de la ordenación urbana contenidas o contenibles en los instrumentos de planeamiento en formación o en trance de reforma (2).

La medida, además de carácter cautelar (por su finalidad de impedir que los hechos consumados se impongan al propósito reformador y vacíen anticipadamente su posible contenido), es:

a) Facultativa, porque normalmente «se puede» acordar, aunque precisamente, como luego veremos, esta característica no se presenta en forma absoluta en la Ley catalana.

b) Temporal: por un año o por dos como máximo.

c) Limitada, tanto en el espacio territorial (para determinadas

(1) Vid. Exposición de Motivos, I.

(2) Como ha dicho la Jurisprudencia del Tribunal Supremo, la razón última de la facultad de suspensión de licencias es evitar que surjan actividades urbanísticas obstaculizadoras de las nuevas previsiones del planeamiento (Sentencias de 10 de abril de 1978 - Ar. 1578-, 3 de octubre de 1980 - Ar. 3831- y 17 de octubre de 1983 -Ar. 5843-). 
áreas o ciertos ámbitos) como materialmente (para concretos usos y actividades); y
d) Sujeta a publicidad formal (3).

Además, dada la naturaleza limitadora de derechos que tiene esta medida, su aplicación ha de ser interpretada restrictivamente. La jurisprudencia del Tribunal Supremo así lo ha declarado con reiteración (4).

Por el mismo motivo de su naturaleza limitadora de derechos, esta medida necesita una explícita cobertura legal y debe ser siempre general, en el sentido de afectar por igual a todos los propietarios o titulares de los derechos a que se refiera (5). No caben suspensiones de licencias ad hoc (6).

Estos criterios, tanto doctrinales como jurisprudenciales, sobre la naturaleza de la suspensión del otorgamiento de licencias son válidos también en su aplicación al régimen especial de Cataluña, que, como luego expondremos, no se diferencia sustancialmente del establecido en la legislación general del Estado.

\section{DistinCIÓN DE OTRAS FIGURAS AFINES}

La doctrina científica (7) ha afirmado que debe diferenciarse la suspensión del otorgamiento de licencias de otras situaciones análogas; pero las situaciones que se citan (las reguladas en los artículos 41,1, a), 42 y 43 del Reglamento de Gestión Urbanística) hay que decir que no son verdaderos casos de suspensión de licencias, sino de concurrencia de circunstancias que hacen imposible el otorgamiento de licencias.

Como dice la Exposición de Motivos de la Ley de Reforma de 1975, la aptitud para edificar la da el Plan, pero el derecho a edifi-

(3) Cfr. Fernández, Tomás-Ramón: Manual de Derecho urbanístico, 2." edición, Madrid, 1981, págs. 73 y 74.

(4) No es posible extender la excepcionalidad limitativa del artículo 22 de la Ley del Suelo de 1956 más allá de su precisión expresiva (Sentencia de 17 de junio de 1963 -Ar. 3262-); este artículo (22) es de interpretación restrictiva (Sentencias de 16 de junio de 1967 -Ar. 3370 - y 7 de marzo de 1972 - Ar. 2064 -); no puede ser jurídicamente viable un impedimento nacido de una reserva mental del órgano de planeamiento en razón a acomodaciones a Planes futuros (Sentencia de 26 de junio de 1974 - Ar. 2708-).

(5) Cfr. Garcfa de Enterría, Eduardo, y Parejo Alfonso, Luciano: Lecciones de Derecho urbanistico, 2:" ed., Madrid, 1981, pág. 342.

(6) Cfr. Perales Madueño, Francisco, y Sanz Boixareu, Pedro-José: «El derecho a la licencia y la suspensión de su otorgamiento», en $R D U$, núm. 62 (1979), pág. 41.

(7) Perales y Sanz, ob. cit., pág. 41. 
car se condiciona, con todas sus consecuencias, al efectivo cumplimiento de las obligaciones y cargas que se imponen al propietario. Si este cumplimiento falta hay imposibilidad de otorgar la licencia.

El suelo urbano está sujeto a la limitación de no poder ser edificado hasta que la respectiva parcela mereciere la calificación de solar (art. 38, 1, de la Ley del Suelo) o se asegure la ejecución simultánea de la urbanización y la edificación (arts. 39 y 40 del Reglamento de Gestión Urbanística), y si se trata de terrenos incluidos en polígonos o unidades de actuación, ha de haber ganado firmeza en vía administrativa el acto de aprobación del proyecto de reparcelación o compensación si uno u otro fueren necesarios para la distribución de los beneficios y cargas del Plan (art. 41, 1, a), del citado Reglamento).

En suelo urbanizable programado, en tanto no se aprueben Planes parciales y se ejecuten (salvo excepción) las correspondientes obras de urbanización, no se puede edificar ni levantar otras instalaciones (arts. 42 y 43 del Reglamento).

En aquellos solares en los que las condiciones de edificación hubieren de concretarse en un posterior Estudio de Detalle no existe suspensión, pero hay imposibilidad de otorgar licencias (art. 15, 4, del Reglamento aprobado por el Decreto de la "Generalitat» 146/ 1984, de 10 de abril, dictado para el desarrollo y aplicación de la Ley $3 / 1984$ ).

Tampoco existe suspensión cuando se aplaza el otorgamiento de licencias porque no se tiene la facultad de edificar en las condiciones propuestas (caso que concurre cuando el proyecto acompañado a la petición de licencia no se ajusta a la normativa vigente y ha de modificarse). El Tribunal Supremo ha abordado este tema (8) en relación con el derecho a indemnización previsto en el artículo 27, 4, de la Ley del Suelo, derecho que procede "en los supuestos en que la única objeción para el otorgamiento es el acuerdo de suspensión, pero no en aquellos en que aun sin este acuerdo la licencia también se hubiera tenido que denegar».

No existe suspensión:

a) Cuando se llega por la vía de hecho a una situación equivalente, lo que no resulta jurídicamente correcto (9).

(8) Vid. Sentencias de 24 de noviembre de 1977 -Ar. $4643-, 6$ de febrero de 1980 - Ar. 585-, 22 de octubre de 1981 - Ar. 4620 - y 13 de diciembre de 1983 -Ar. 6337-.

(9) Sentencias de 27 de marzo y 3 de octubre de 1980 - Ar. 2246 y 3831-. 
b) Cuando se utiliza la fórmula «no se concede por ahora», equiparada por la jurisprudencia a la negativa pura y simple (10); y

c) Cuando se deniega la licencia - lo que no está permitidoso pretexto de futuros proyectos o planes, carentes en el momento de la denegación de efectiva vigencia (11).

Finalmente, la suspensión de licencias, medida de protección de la legalidad urbanística, que suspende, no el otorgamiento de la licencia, sino los efectos de una licencia ya concedida, es una situación distinta de la suspensión del otorgamiento de licencias de que ahora tratamos.

\section{DERECho COMPARADO}

La suspensión del otorgamiento de licencias no es una institución genuinamente española; aparece también en el Derecho urbanístico alemán, en el francés y en el italiano.

La Ley Federal alemana del Suelo de 29 de junio de 1960 incluye la suspensión (interdicción de toda alteración de la situación urbanística) entre las "medidas para salvaguardar el Plan de edificación», y la autoriza cuando se va a redactar, cambiar, ampliar o anular un Plan con referencia a las obras de alguna consideración o que aumenten el valor de los solares y a las instalaciones que puedan alterar el medio ambiente. La duración de la suspensión puede llegar a cuatro años, y si se extiende a más plazo genera una indemnización pecuniaria a favor del interesado por los daños y perjuicios que se le hubieren irrogado (arts. 14, 15, 17 y 18).

El Código francés del Urbanismo regula las técnicas de establecimiento de suspensiones (sursis d statuer). La suspensión ha de ser motivada y no puede exceder de dos años; pasado este plazo ha de adoptarse una decisión en la forma y plazo habituales (arts. L 111-8 y sigs.).

En el Derecho italiano las medidas de salvaguardia fueron introducidas por la Ley de 3 de noviembre de 1952, número 1.902, que reconoció la facultad de suspender las licencias por un período máximo de dos años cuando lo proyectado fuese contrario a las deter-

(10) Sentencia de 23 de noviembre de 1979 - Ar. 4064-.

(11) Sentencias de 24 de octubre de 1974 -Ar. 3826-, 24 de febrero de 1974 -Ar. 1159 -, 31 de enero, 23 de abril, 13 de mayo y 3 de junio de 1980 -Ar. 307, 2597,3802 y 3139 - y 13 de octubre de 1981 - Ar. 4148-. 
minaciones de los Planes generales o particulares adoptados por el Municipio. Sucesivos textos legales han modificado esta primera Ley con la finalidad de ofrecer mayores garantías al administrado.

\section{ANTECEDENTES y EVOLUCión De SU RÉGimen EN EL DERECHo ESPAÑOL}

La Ley del Suelo de 12 de mayo de 1956 introdujo la suspensión de licencias en su artículo 22, pero sólo como medida preparatoria del planeamiento y con el fin de estudiar el Plan de ordenación o su reforma. Esta medida fue recogida también en la Ley 197/1963, de 28 de diciembre, sobre centros o zonas de interés turístico nacional (artículo 8..$^{\circ}$.

La jurisprudencia del Tribunal Supremo interpretó restrictivamente desde un principio, como ya hemos puesto de relieve, la aplicación de la suspensión, y negó la posibilidad de utilizarla con referencia a las obras de reforma o a la autorización de actividades industriales (12), destacando que la suspensión requería siempre un acuerdo específico, así como la publicación de este acuerdo (13).

Ya en 1965 (14), comentando el citado artículo 22, pusimos de relieve lo siguiente:

1. Que la suspensión de todas las licencias con la finalidad de reformar el Plan era una medida de excesivo rigor que colapsaba la construcción con un efecto perturbador, por lo que entendiamos que la norma legal debía completarse para permitir que, aun acordada la suspensión, pudieran autorizarse los proyectos de obras que estuvieran de acuerdo con la ordenación vigente y con los Planes en estudio.

2. Que la suspensión de licencias debería ser un efecto inmediato y automático de la aprobación inicial; siempre, claro está, con una determinada duración y en relación con los proyectos de edificación que estuvieren en contradicción con los Planes inicialmente aprobados.

La Ley de Reforma de 1975 modificó el artículo 22 de la Ley del Suelo de 1956 de manera que conservando la suspensión facultativa o potestativa - aunque con algunas matizaciones- introducía la

(12) Vid. Sentencias de 17 de junio de 1963 y 9 de mayo de 1970.

(13) Sentencia de 28 de mayo de 1969 - Ar. 2769-.

(14) Vid. El derecho y la obligación de edificar, pág. 146. 
suspensión de efectos automáticos dimanante de la aprobación inicial. Esta modificación quedó recogida en el artículo 27 del texto refundido aprobado por el Real Decreto 1346/1976, de 9 de abril, y fue desarrollada en el Reglamento de Planeamiento (arts. 117 a 122, ambos inclusive), aprobado por el Real Decreto 2159/1978, de 23 de junio. Un análisis muy crítico de este texto reglamentario fue en su día realizado por José Luis CASTRo Troncoso (15).

Con referencia a la suspensión automática introducida por la reforma de 1975, la doctrina ha puesto de relieve lo siguiente:

a) Se produce no como un acto preparatorio del procedimiento de formación de los Planes de ordenación urbana, sino como un efecto o consecuencia inseparable del acto con que formalmente comienza dicho efecto, esto es, el acto de aprobación inicial; y

b) Aunque deriva, como acabamos de decir, del acto de aprobación inicial, no se produce con un grado tal de automatismo como para que le sea absolutamente acertado el calificativo de «suspensión automática» (16).

Con posterioridad, como es sabido, el régimen de suspensión del otorgamiento de licencias fue regulado nuevamente por el Real Decreto-ley 16/1981, de 16 de octubre (art..$^{\circ}$ ), en el que expresamente se decía que su aplicación en el territorio de las Comunidades Autónomas no afectaría a lo dispuesto en sus respectivos Estatutos (Disposición final sexta) en razón, sin duda, a que dichas Comunidades podían asumir competencias en materia de urbanismo (artículo $148,1,3^{\circ}$, de la Constitución), y así lo han hecho en los Estatutos aprobados, entre ellos en el de Cataluña (art. 9., 9), aprobado por la Ley Orgánica 4/1979, de 18 de diciembre.

El citado Real Decreto-ley mantiene las dos clases de suspensión, potestativa y automática, establecidas a partir de la Ley de Reforma.

(15) Vid. «La suspensión del otorgamiento de licencias en el Reglamento de Planeamiento», en $R D U$, núm. 62 (1979).

(16) Cfr. Perales y Sanz, ob. cit., págs. 41 y 47. 


\section{ORDENAMIENTO URBANISTICO DE CATALUÑA}

\section{PRoyecto DE Ley aUtonómica}

El Proyecto de Ley de Medidas de Adecuación del Ordenamiento Urbanístico de Cataluña fue aprobado por el "Consell Executiu» o Consejo de Gobierno de la "Generalitat» el 21 de octubre de 1982, y remitido al "Parlament», fue insertado en el Bulleti Oficial número 110, de 20 de diciembre siguiente.

La Exposición de Motivos del Proyecto no se refería a la suspensión del otorgamiento de licencias. Buscando una justificación a la regulación de esta materia en el articulado, podría encontrarse en la necesidad de aclarar la vigencia en Cataluña del Real Decreto-ley $16 / 1981$, que había planteado dudas, porque su Disposición final sexta, a la que ya hemos aludido, salvaba la constitucionalidad del Real Decreto-ley, pero no resolvía en concreto si se aplicaba o no en el territorio de Cataluña, y esta incertidumbre había dividido a las Corporaciones locales entre las que seguían aplicando la Ley del Suelo y las que ponían en práctica la nueva normativa.

El Proyecto de Ley dedicaba a la suspensión del otorgamiento de licencias el Capítulo I del Título II (Del procedimiento para aprobar el planeamiento urbanístico y de los proyectos para desarrollarlo), que comprendía los artículos $30^{\circ}, 4 .^{\circ}$ y $5 .^{\circ}$

Aparte de las enmiendas a la totalidad - que no prosperaronpresentadas por varios grupos parlamentarios, se formularon en relación con el tema de la suspensión de licencias varias enmiendas que contenían las siguientes propuestas:

A) Adicionar a las determinaciones que constituían la modificación del régimen urbanístico las referentes a los espacios señalados como sujetos a reforma interior en suelo urbano y a los edificios a incluir en el Catálogo de Protección Artística (17).

B) Suprimir los apartados 1 y 2 del artículo $3 .^{\circ} ; \operatorname{los} 1$ y 2 del artículo $4 .^{\circ}$, y todo el artículo $5 .^{\circ}$ por entender que el tema venía regulado por el Reglamento de Planeamiento, vigente en Cataluña, con más rigor que en la modificación propuesta (18).

C) Sustituir en el artículo $4 .^{\circ}, 1$, la frase se «faculta para la suspensión» por la de «implica la imposibilidad de otorgamiento»; en

(17) Enmienda del Diputado señor Ferrán Pont.

(18) Enmienda del Grupo Socialista. 
el $4 .^{\circ}, 2, d$ ), adicionar, como determinación que constituye modificación del régimen urbanístico, la alteración del coeficiente de edificación neta de una zona y de los parámetros de edificación fundamentales (altura, ocupación de suelo y profundidad edificable), y en el artículo $5^{\circ}, 1$, efectuar su sustitución por un texto más simple (19).

D) Adicionar un párrafo 3 en el artículo $30^{\circ}$ sobre publicación de la suspensión en el Boletín Oficial de la Provincia y en el Diari Oficial de la Generalitat, y efectuar una sustitución en el párrafo 1 del artículo $4 .^{\circ}$ en el sentido de que la aprobación inicial determinará por sí sola la suspensión, y una adición de un párrafo 3 , sobre la suspensión determinada por la iniciación del expediente de reparcelación, por coherencia con el artículo 98 de la Ley del Suelo (20).

El Proyecto de Ley fue dictaminado por la Comisión de Política Territorial del «Parlament» el 9 de diciembre de 1983 (21). Este dictamen coincide con el texto después aprobado, excepto en el párrafo 3 del artículo $3 .^{\circ}$, que utiliza la conjunción copulativa «y» para expresar que el acuerdo de suspensión habrá de publicarse en el Diari Oficial de la Generalitat y en el Boletín Oficial de la Provincia, mientras que el texto definitivo emplea la conjunción disyuntiva «o» $y$ añade al final «en su caso».

\section{Ley de Medidas de Adecuación}

\section{A) Tratamiento de la suspensión del otorgamiento de licencias}

La Ley del Parlamento de Cataluña 3/1984, de 9 de enero, dedica al tema de la suspensión del otorgamiento de licencias los artículos $3 .^{\circ}, 4 .^{\circ}$ y $5 .^{\circ}$ (de igual numeración que la utilizada en el Proyecto de Ley), manteniendo la dualidad de suspensiones potestativa (artículo $3 .^{\circ}$ ) y automática (art. $4 .^{\circ}$ ), diferenciadas, como ha puesto de relieve LLISET (22), tan sólo por el momento y por la finalidad en que se producen; quizá también, a la luz de la nueva Ley, por el carácter potestativo $\mathrm{u}$ obligatorio, según veremos luego al analizar la suspensión automática, tal y como ha quedado en la versión definitiva del texto legal que comentamos. El artículo $5 .^{\circ}$ contiene, final-

(19) Enmienda del PSUC.

(20) Enmienda de Esquerra Republicana.

(21) Vid Butlleti Oficial, núm. 169, de 15 de diciembre.

(22) Modificaciones urgentes de la Ley del Suelo, Madrid, 1982, pág. 135. 
mente, disposiciones que se refieren a los dos mencionados tipos de suspensión.

\section{B) Suspensión potestativa}

De acuerdo con los precedentes legales la admite también la nueva Ley y la regula, como hemos dicho, en el artículo $3 .^{\circ}$

La pueden acordar los órganos competentes para la aprobación inicial de instrumentos de planeamiento general, especial, parcial o de los Estudios de Detalle.

Los Ayuntamientos serán, por regla general, los órganos competentes para acordar la suspensión; lo pueden ser también las Diputaciones Provinciales cuando el Plan se vaya a extender a más de un término municipal (art. 40, 1, a), de la Ley del Suelo y art. 126, 2, del Reglamento de Planeamiento), así como, en su caso, las Entidades urbanísticas especiales (arts. 43 de la Ley y 147, 1, del Reglamento).

Siguiendo el precedente del artículo 117 del Reglamento de Planeamiento, el Reglamento de la Ley catalana incluye entre los instrumentos de planeamiento que pueden motivar el acuerdo de suspensión del otorgamiento de licencias los Programas (art. 7., 1). Esta inclusión es, sin duda, una mera consecuencia del carácter intermedio que tiene el Programa de Actuación Urbanística entre el Plan General y el Plan Parcial. Sin embargo, tal inclusión es discutible porque sin el Programa de Actuación las posibilidades de edificación en el suelo urbanizable no programado son escasas y el riesgo que se corre con la no suspensión de licencias no tiene importancia porque afecta sólo a las autorizaciones que podrían solicitarse en los limitadísimos supuestos de edificaciones aisladas destinadas a vivienda familiar (art. 85 de la Ley del Suelo), y si la suspensión viene motivada por la modificación del Programa, si aún no se ha aprobado el Plan Parcial, no es posible otorgar licencias (23), según hemos advertido anteriormente.

La finalidad de la suspensión coincide con la que figura también en el artículo 8., 1 , del Real Decreto-ley 16/1981: estudiar la formación o reforma de los citados instrumentos de planeamiento.

Las licencias afectadas son de la misma clase que las aludidas en el régimen general: de parcelación de terrenos, de edificación y de demolición en ámbitos determinados. Se incluyen, por tanto, las

(23) Perales y Sanz, ob. cit., pág. 44. 
licencias de demolición, como también las había incluido el Real Decreto-ley 16/1981, quizá para salvar el reparo de dudosa legalidad del artículo 118 del Reglamento de Planeamiento que había señalado CASTRo TRONcoso (24). El nuevo precepto, en lugar de referirse a «áreas determinadas», habla de «ámbitos determinados»; modificación que consideramos intrascendente.

Queda en pie la cuestión de si la suspensión sólo afecta a las obras nuevas o de nueva planta, como ha entendido la mayor parte de la doctrina (BOQUERA y CASTRo TRONCoso, entre otros) y la jurisprudencia (25), con una interpretación restrictiva, o si, como opinan García DE ENTERRÍa y PAREJo (26), la obligada interpretación sistemática de los preceptos legales conduce a la conclusión de que la expresión "licencias de edificación" utilizada incluye todas las autorizaciones preceptivas legalmente para «actos de edificación» según el artículo 178, 1, de la Ley del Suelo, porque el concepto de edificación, que es genérico, no puede identificarse con el específico de "obra de nueva planta», relativo tan sólo a una de las actividades propias de la edificación. Sin embargo, que el Real Decreto-ley y la Ley catalana hayan incluido expresamente las licencias de demolición parece que está negando esta tesis y abriendo paso a una tercera postura, por nosotros sostenida, según la cual la suspensión no afectaría a las obras de reforma ni a la autorización de actividades industriales cuando se refieran a edificios existentes y no supongan ampliación ni afecten a la estructura de la construcción. Esta es, en definitiva, la postura que acoge el Reglamento de Planeamiento cuando establece que la suspensión no podrá referirse a las obras de reforma, salvo que por la trascendencia de ésta sea equiparable a una reedificación del edificio, no justificable por razones de urgencia o que suponga un aumento de volumen edificable (artículo 118,1$)(27)$.

Los efectos de esta suspensión potestativa «no podrán durar más de un año" (art. $3 .^{\circ}, 2$, de la Ley), lo que equivale a decir, en

(24) Obra citada.

(25) Vid. Sentencias de 20 de junio de 1963 y 7 de marzo de 1972.

(26) Lecciones..., cit., pág. 342.

(27) Recientemente el Tribunal Supremo, con referencia al Plan Especial del conjunto artístico de la ciudad de Oviedo, ha declarado que la suspensión de licencias podía alcanzar a las de demolición conforme a lo establecido de manera expresa en el artículo 27 de la Ley del Suelo (al estar encaminadas a la «edificación»), singularmente tratándose de Planes Especiales para la conservación de ciertos inmuebles (Sentencia de 17 de octubre de 1983 -Ar. 5843-). 
expresión del Real Decreto-ley, que esta suspensión «se extinguirá en todo caso en el plazo de un año" (art. 8. $.^{\circ}, 3$ ).

El acuerdo de suspensión potestativa se publicará en el Diari Oficial de la Generalitat o en el Boletín Oficial de la Provincia en su caso (art. 3. $.^{\circ}, 3$, de la Ley). Ya nos hemos referido anteriormente al origen parlamentario de este texto. El Reglamento añade que la publicación ha de hacerse también en uno de los diarios de más divulgación en Cataluña (art. $7 .^{\circ}, 3$ ), precepto análogo, aunque sin referencia a Provincias, al del artículo 117, 2, del Reglamento de Planeamiento. Por otra parte, también por vía reglamentaria se ha aclarado la disyuntiva de la publicación en el Diari Oficial o en el Boletín Oficial: cuando la suspensión hubiere sido acordada por la Administración local, la publicación ha de hacerse en el Boletín Oficial de la Provincia, y cuando haya sido adoptada por la Administración de la Generalidad, en el Diari Oficial de la Generalitat (artículo 64).

\section{C) Suspensión automática}

Aparece regulada en el artículo $4 .^{\circ}$ de la Ley del Parlamento de Cataluña y se instrumenta como obligación de la Administración actuante.

La suspensión afecta a las tres mismas clases de licencias que comprende la potestativa:

- De parcelación.

- De edificación; y

- De demolición.

No se refiere tampoco a todo el territorio objeto de ordenación por el instrumento de planeamiento aprobado inicialmente, sino sólo a «los ámbitos para los que las nuevas determinaciones comporten modificación del régimen urbanístico». En forma muy parecida se expresa el artículo 8. ${ }^{\circ}, 2$, del Real Decreto-ley.

El Tribunal Supremo ha destacado que la suspensión del otorgamiento de licencias, como precepto restrictivo que es de las facultades para la edificación y sus derivados, requiere para su efectividad, de una parte, perimetración previa totalmente determinada de los terrenos que por excepción trata de comprender, y de otra parte, una también previa publicidad de esa medida de excepción (28).

(28) Sentencia de 2 de marzo de 1971 -Ar. 1190-. 
Además, la necesidad de concretar expresamente las zonas objeto de suspensión automática tiene un claro fundamento porque en ella se conocen - al menos en ese momento de la aprobación inicial- las zonas, cuyo nuevo régimen resulta incompatible con la anterior ordenación, por lo que es, además de posible, lógica la delimitación de los ámbitos territoriales afectados por la suspensión (29).

Como novedad importante añade este artículo $4 .^{\circ}$ de la Ley autonómica que constituyen modificación del régimen urbanístico las determinaciones que comporten:

a) Cambio en la clasificación del suelo.

b) Afectación de terrenos para sistemas (30).

c) Modificación de los usos globales admitidos en un sector. El Reglamento ha aclarado que, a estos efectos, se entiende por sector urbano el ámbito de asignación de usos globales por el planeamiento y, por modificación de éstos, la sustitución de una categoría por otra entre las categorías de usos residencial, industrial y terciario (art. 10, 1).

d) Modificación del coeficiente de edificación neta de una zona; es decir, según el Reglamento, modificación de la relación existente entre la superficie de techo edificable y la superficie de las parcelas susceptibles de edificación para su aprovechamiento privado (art. 10, 2).

El párrafo 2 del artículo 4..$^{\circ}$ de la Ley, que acabamos de exponer, muy interesante a efectos de garantizar la seguridad jurídica del administrado, se ve, sin embargo, un tanto desvirtuado por lo dispuesto en el siguiente párrafo:

«3. Además, en el momento de la aprobación inicial la Administración actuante podrá acordar la suspensión de la concesión de las licencias mencionadas en el apartado 1 de este artículo en los ámbitos para los que se

(29) Cfr. Perales y Sanz, ob. cit., pág. 52.

(30) Podemos recordar a este respecto que el acuerdo del Consejo Pleno de la Corporación Metropolitana de Barcelona, de 6 de febrero de 1976, que aprob6 inicialmente el Plan General Metropolitano, estableció expresamente que la suspensión de licencias afectaba al suelo calificado para sistemas.

La sentencia de 28 de mayo de 1984 (Ar. 3136) sostiene que la suspension de licencias es consecuencia necesaria de la aprobación inicial, y como ésta es un acto trámite, la suspensión es irrecurrible, pero la irrecurribilidad cede ante la existencia de cualquiera de las causas determinantes de la nulidad radical proclamada por el artículo 47 de la Ley de Procedimiento administrativo. 
pretenda alcanzar objetivos urbanísticos concretos, que habrán de ser explicitados y justificados».

Aquí la Administración no viene obligada, sino que puede acordar la suspensión, pero la única garantía que el precepto establece en favor del administrado es la exigencia de que los objetivos que se pretenda alcanzar habrán de ser «explicitados y justificados». Así como la expresión de los objetivos se hará (aunque quizá no expresando «clara y terminantemente» el objetivo), nos tememos que la justificación se reducirá en muchos casos a una explicación o comentario de los objetivos.

A este respecto el Reglamento dice que los objetivos podrán referirse a:

1. Salvaguardar la armonía de los conjuntos de edificios de carácter artístico, histórico, arqueológico, típico o tradicional, o bien, sin existir conjunto, a algún edificio de gran importancia o calidad con alguna de las características indicadas; y

2. Impedir la ejecución de aquellas condiciones de edificación que desfiguren la construcción existente y predominante de los anteriores conjuntos, el ordenamiento físico de los frentes marítimos y las panorámicas con fuerte identidad en los paisajes abiertos (artículo 11).

No constituye novedad el párrafo 4 de este artículo $4 .^{\circ}$ de la Ley autonómica, referente a la suspensión determinada por la iniciación del expediente de reparcelación - párrafo introducido como consecuencia de la aceptación de una enmienda a la que anteriormente nos hemos referido-, que se formula de la misma manera que aparece en el artículo 97, 2, de la Ley del Suelo; es decir, así:

«4. La iniciación del expediente de reparcelación comporta, sin que sea precisa declaración expresa, la suspensión de la concesión de licencias de parcelación y de edificación en el ámbito del polígono o de la unidad de actuación hasta que el acuerdo aprobatorio de la reparcelación sea firme en vía administrativa».

La Ley no se limita a decir que los acuerdos de suspensión han de adoptarse con las formalidades previstas reglamentariamente (como dice también el art. $8^{\circ}, 5$, del Real Decreto-ley 16/1981) y que es preciso delimitar explícitamente los ámbitos afectados, sino que, como interesante novedad, añade que dicha delimitación ha de hacerse confeccionando un plano de delimitación de los ámbitos su- 
jetos a suspensión de licencias, en el que aparecerán, a escala adecuada y con detalle y claridad suficientes, todos estos ámbitos (artículo $\left.5 .^{\circ}, 1\right)$. Esta exigencia es interesante en cuanto va destinada a proporcionar información y seguridad jurídica al administrado. Quizá podría alegarse que no necesariamente el precepto habría de tener rango legal, sino que hubiera bastado incluirlo en una disposición reglamentaria. Curiosamente el Reglamento se limita a reproducir el precepto legal y no concreta, como hubiera sido deseable, ni cuál es la escala adecuada ni cuáles deben ser el detalle y claridad suficientes; lo que sí dice es que el plano quedará a disposición del público en las oficinas de la Administración actuante durante el plazo de suspensión de licencias (art. 12,3), y añade, con expresión no muy feliz, que los acuerdos de suspensión explicitarán su alcance (¿acaso sin necesidad de plano?) cuando sólo se limiten al otorgamiento de licencias referidas a determinado uso (art. 12, 2).

Los demás párrafos de este artículo $50^{\circ}$ de la Ley están destinados a determinar la duración de la suspensión automática, distinguiendo al efecto los siguientes supuestos:

1. Si antes de transcurrir el plazo de un año previsto para la duración de la suspensión potestativa (art. $\left.3 .^{\circ}, 2\right)$ se acuerda la aprobación inicial. En este caso la Administración actuante podrá hacer uso de la suspensión prevista como automática (la establecida en el artículo 4..$^{\circ}$; pero los efectos de esta segunda suspensión se extinguirán definitivamente una vez transcurridos dos años desde la vigencia del acuerdo adoptado para estudiar el Plan o la reforma del mismo (art. 5., 2 ). Quizá resulta más acertado que hablar, como lo hace el Real Decreto-ley 16/1981, de mantenimiento de la suspensión (artículo $8 .^{\circ}, 3$ ), porque puede variar su ámbito territorial y material.

2. Si la aprobación inicial se produce una vez transcurrido el plazo de un año previsto para la duración de la suspensión potestativa (art. $3^{\circ}, 2$ ), la suspensión decidida con motivo de la aprobación inicial tendrá también la duración máxima de un año, contado a partir de la publicación del acuerdo de suspensión (art. 5.․, 3).

3. Si con anterioridad al acuerdo de aprobación inicial no se hubiere adoptado la suspensión potestativa (art. 3., 1 ), la suspensión que se decida con motivo de la aprobación inicial tendrá una duración máxima de dos años (art. 5.,4); precepto que concuerda con el artículo $8 .^{\circ}, 3$, del Real Decreto-ley 16/1981. 
De esta regulación se desprende - como sucedía ya en el Real Decreto-ley 16/1981 - que los dos tipos de suspensión no son compatibles ni acumulables y que la medida suspensiva no puede tener una duración superior a dos años (31).

Los efectos de la conclusión del plazo de duración de la suspensión están acertadamente descritos en la sentencia de 26 de octubre de 1983 (Ar. 5979) en la forma siguiente:

«... cuando por virtud del paso del tiempo finaliza el plazo de suspensión, la normativa urbanística, comprimida en sus efectos por el acuerdo de suspensión, desaparecida ésta recupera toda su virtualidad ordenadora y operativa, y abre paso, mediante su aplicación, a los proyectos (de edificación) que resulten conformes con la misma».

\section{D) Otras disposiciones}

Según el Reglamento, si el acuerdo de suspensión se adopta por un plazo inferior al máximo admitido pueden prorrogarse sus efectos hasta agotarlo siempre que esta decisión se adopte antes de terminar el inicialmente decidido y se observen los mismos requisitos de publicación (art. 14).

En todos los casos los efectos de la suspensión se extinguirán con la entrada en vigor del instrumento de planeamiento de que se trate por razón de la aprobación definitiva del mismo (art. 5., 5, de la Ley autonómica) (32).

Una vez extinguidos los efectos de la suspensión no se podrán acordar nuevas suspensiones en los ámbitos por ella afectados por idéntica finalidad en los cinco años siguientes (art. $5^{\circ}, 6$ ).

(31) El tema de la compatibilidad de las suspensiones ha sido abordado también por la Jurisprudencia del Tribunal Supremo, pero su doctrina no puede generalizarse y ha de analizarse con referencia al supuesto concreto contemplado en cada caso. Así, con aplicación al texto reformado de la Ley del Suelo, la sentencia de 15 de noviembre de 1983 (Ar. 6012) consideró totalmente compatibles una suspensión operada porque se había aprobado con carácter inicial un proyecto de adaptación del Plan General, y otra suspensión, ésta potestativa, que tenía por finalidad atemperar la edificación de determinados sectores a los límites permitidos de 75 viviendas por hectárea, precisamente en atención a reclamaciones formuladas en período de información pública del proyecto de adaptación del Plan General. Esta sentencia se apoyaba en las consideraciones hechas por otras dos anteriores: la de 28 de septiembre de 1980 (Ar. 5088), que admitía la compatibilidad por no referirse las suspensiones al mismo ámbito, y la de 23 de junio de 1981 (Ar. 2732), que había aceptado la suspensión en virtud de dos aprobaciones iniciales por obedecer a variaciones de proyecto de planeamiento introducidas por impugnaciones o reclamaciones presentadas con motivo de la información pública.

(32) Este precepto concuerda con el artículo $8 .^{\circ}, 3$, del Real Decreto-ley:

Según la sentencia de 12 de mayo de 1984 (Ar. 3122), el derecho a edificar en potencia es preexistente, salvo las incompatibilidades con la normativa urbanística, en el instante de presentación de las solicitudes de licencia. 
La prohibición de nuevas suspensiones -establecida en forma similar a la prevista en el párrafo 4 del art. $8 .^{\circ}$ del Real Decretoley - viene condicionada, aparte por el transcurso del plazo de cinco años -introducido ya por el art. 22, 2, de la Ley del Suelo de 1956, y que en principio no plantea gran dificultad de interpretación-, por la identidad con el ámbito a que se había referido la suspensión, y estos dos condicionantes de la prohibición sí que plantean o pueden plantear problemas.

El Reglamento - suponemos que con la intención de delimitar el concepto- añade que se entiende como idéntica finalidad la redacción de un Plan, Normas, Programa o Estudio de Detalle, o su revisión o modificación, con la misma naturaleza que el que motivó la primera suspensión (art. 15, 2), lo cual nada aclara porque se limita a sustituir un concepto (finalidad) por otro (naturaleza) igualmente indeterminado; ahora bien - sigue diciendo el Reglamento-, después de haberse suspendido el otorgamiento de licencias con ocasión de la redacción o tramitación de una figura de planeamiento general, o de su reforma, sólo podrán adoptarse nuevos acuerdos de suspensión con ocasión de la redacción y tramitación de sólo una figura de planeamiento que desarrolle aquél (art. 15, 3). Este segundo precepto reglamentario sí que nos parece claro y limitativo, y no nos extrañaría que tuviera que ser invocado alguna vez frente a la Administración, que unas veces por propia iniciativa y otras a instancia de parte se muestra muy inclinada a reformar el planeamiento de desarrollo (33).

\section{CONCLUSIONES}

La precedente exposición nos permite sentar, entre otras conclusiones, las siguientes:

1. $\quad$ La Ley del Parlamento de Cataluña se ha propuesto que quede claro para lo sucesivo cuál es el régimen aplicable en Cataluña en relación con la suspensión del otorgamiento de licencias.

(33) La ya citada sentencia de 15 de noviembre de 1983 (Ar. 6012) ha declarado que dentro de una misma finalidad, deducible estrictamente de los vocablos «revisión», "adaptación» y «modificación», es legalmente permitido que la falta de identidad radique en puntos concretos, sean éstos de carácter principal o más o menos secundarios o accesorios, con tal de que no hubieren constituido anteriormente objeto concreto de suspensión, es decir, que los términos de las respectivas intenciones no resultaran superpuestos acotando un mismo ámbito de realidad. 
2. $\quad$ La Ley mantiene la dualidad de suspensiones, potestativa y automática, y las considera, al igual que el Real Decreto-ley 16/ 1981 - normativa que recoge bastante fielmente-, incompatibles y no acumulables en su vigencia temporal.

3. ${ }^{\text {a }}$ La Ley autonómica deja claro el tema de la duración de la suspensión, al que dedica especial atención.

4. ${ }^{\mathrm{a}}$ La Ley introduce, como novedades importantes, las siguientes:

a) El carácter, en cierto modo, obligatorio de la suspensión automática.

b) La definición de lo que constituye modificación del régimen urbanístico.

c) La exigencia de confeccionar un plano de delimitación de los ámbitos sujetos a suspensión de licencias. 


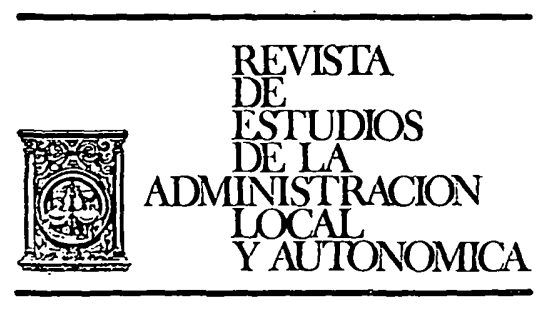

\section{JURISPRUDENCIA}


REALA-1985, núm. 226. CARCELLER FERNANDEZ, ANTONIO. LA SUSPENSION DEL OTORGAMIEN...

REALA-1985, núm. 226. CARCELLER FERNANDEZ, ANTONIO. LA SUSPENSION DEL OTORGAMIEN... 